\title{
Fallopian Tube
}

National Cancer Institute

\section{Source}

National Cancer Institute. Fallopian Tube. NCI Thesaurus. Code C12403.

One of a pair of tubes that extend from the uterus to each of the ovaries. Following ovulation the egg travels down the fallopian tube to the uterus where fertilization may or may not occur. 